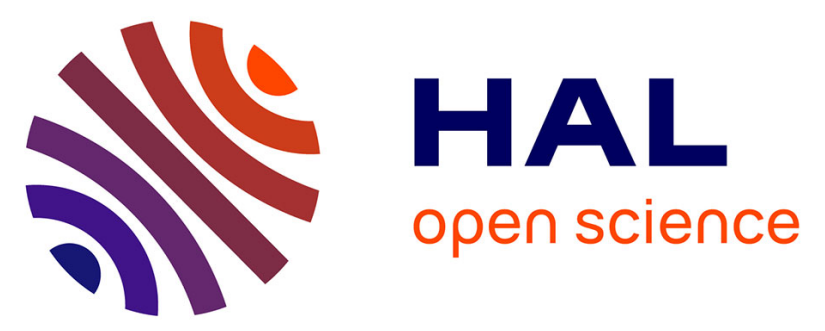

\title{
Biochemical and thermodynamic characterization of mutated $\beta 1,4$-galactosyltransferases 7 involved in the progeroid form of the Ehlers-Danlos syndrome
}

Sophie Rahuel-Clermont, Franck Daligault, Marie-Helene Piet, Sandrine Gulberti, Patrick Netter, Guy Branlant, Jacques Magdalou, Virginie Lattard

\section{To cite this version:}

Sophie Rahuel-Clermont, Franck Daligault, Marie-Helene Piet, Sandrine Gulberti, Patrick Netter, et al.. Biochemical and thermodynamic characterization of mutated $\beta 1$,4-galactosyltransferases 7 involved in the progeroid form of the Ehlers-Danlos syndrome. Biochemical Journal, 2010,432 (2), pp.303-311. 10.1042/BJ20100921 . hal-00535585

\author{
HAL Id: hal-00535585 \\ https://hal.science/hal-00535585
}

Submitted on 12 Nov 2010

HAL is a multi-disciplinary open access archive for the deposit and dissemination of scientific research documents, whether they are published or not. The documents may come from teaching and research institutions in France or abroad, or from public or private research centers.
L'archive ouverte pluridisciplinaire HAL, est destinée au dépôt et à la diffusion de documents scientifiques de niveau recherche, publiés ou non, émanant des établissements d'enseignement et de recherche français ou étrangers, des laboratoires publics ou privés. 


\title{
Biochemical and thermodynamic characterization of mutated $\beta 1,4-$ galactosyltransferases 7 involved in the progeroid form of the Ehlers- Danlos syndrome
}

\author{
Sophie RAHUEL-CLERMONT ${ }^{\dagger}$, Franck DALIGAULT ${ }^{*}$, Marie-Helene PIET ${ }^{*}$, Sandrine \\ GULBERTI*, Patrick NETTER*, Guy BRANLANT ${ }^{\dagger}$, Jacques MAGDALOU* and Virginie \\ LATTARD $^{* 1}$
}

*Physiopathologie, Pharmacologie et Ingénierie Articulaires, Unité Mixte de Recherche 7561 CNRS-Nancy Université, BP 184 Faculté de Médecine, Vandoeuvre-Les-Nancy, France

${ }^{\dagger}$ ARN-RNP-structure fonction-maturation, Enzymologie Moléculaire et Structurale, Unité Mixte de Recherche 7214 CNRS-Nancy Université, Faculté des Sciences et Techniques, BP 239 Vandoeuvre-Les-Nancy, France

Short Title: mutated $\beta 1,4-$ GalTs7 and Ehlers-Danlos syndrome

Three mutations of the $\beta 4$ GALT7 gene corresponding to A186D, L206P and R270C were identified in patients with the progeroid form of the Ehlers-Danlos syndrome and described to be associated with reduction or loss of activity of the $\beta 1,4$-galactosyltransferase 7 . But the molecular bases of the reduction or loss of activity remain to be determined. In the present study, wild-type, A186D, L206P and R270C $\beta 1,4-$ GalT7s were expressed in CHO618 cells as membrane proteins and in Escherichia coli as soluble maltose binding-fusion proteins. Ability of expressed proteins to transfer galactose from donor to acceptor substrate was systematically characterized by kinetic analysis. The physicochemical properties of soluble proteins were explored by isothermal titration calorimetry which is a method of choice to have access to the thermodynamic parameters of the binding of substrates. Altogether, the results showed that (i) the L206P mutation abolished the activity when L206P $\beta 1,4$ GalT7 was either inserted in the membrane or expressed as a MBP-full length $\beta 1,4 \mathrm{GalT7}$, (ii) the A186D mutation weakly impaired the binding of the donor substrate, (iii) the R270C mutation strongly impaired the binding of the acceptor substrate. Moreover, ex vivo consequences of the mutations were investigated by evaluating the priming efficiency of xylosides on glycosaminoglycan chain initiation. The data demonstrate (iv) a quantitative effect on the glycosaminoglycan biosynthesis depending on the mutations. While the GAG biosynthesis was fully inhibited by the L206P mutation and decreased by the R270C mutation, the A186D mutation did not affect the GAG biosynthesis severely.

Key words: $\beta 1$,4-galactosyltransferase; Ehlers-Danlos syndrome; mutation; substrate binding; isothermal titration calorimetry; kinetics; glycosaminoglycan

Abbreviations used: PG, proteoglycan ; GAG, glycosaminoglycan ; HP, heparin ; HS, heparan-sulfate ; CS, chondroitin-sulfate ; DS, dermatan-sulfate ; ECM, extracellular matrix; ITC, isothermal titration calorimetry ; GalT, galactosyltransferase ; MBP, maltose-binding protein ; Gal, galactose ; Xyl, xylose ; pNP-Xyl, 4-Nitrophenyl- $\beta$-D-xylopyranoside ; 4MUXyl, 4-Methylumbelliferyl- $\beta$-D-xylopyranoside ; WT, wild-type.

${ }^{1}$ To whom correspondence should be addressed (E-mail: v.lattard@ vetagro-sup.fr) 


\section{INTRODUCTION}

Ehlers-Danlos syndrome (EDS) is a heterogeneous group of more than 10 inherited connective-tissue disorders characterized by joint hypermobility, cutaneous fragility, and hyperextensibility [1]. All involve a genetic disorder defect in collagen and connective-tissue synthesis and structure. The different types of EDS are classified according to the signs and symptoms that are manifested and each type of EDS is a distinct disorder that "runs true" in a family. To date, among those, only 5 patients have been described with the progeroid variant of EDS, which is a very rare disorder characterized by a premature aging phenotype with a loose, elastic skin, failure to thrive, joint laxity, psychomotor retardation, hypotonia and macrocephaly [2-4]. Biochemically, aberrant glycosaminoglycan (GAG) substitution of proteoglycans $(\mathrm{PG})$ has been observed in those patients $[5,6]$.

PGs are found predominantly in the extracellular matrix (ECM) or associated with the cell surface of most eukaryotic cells. Most often, PGs act as molecular organizers of the ECM and as promoters of cell adhesion [7]. They also fulfil a variety of other biological functions, such as growth modulation, ionic filtration and biomechanical lubrication [8-11]. Their biological roles are closely related to the presence and the composition of the GAG chains, which contain binding sites for various growth factors, cytokines, morphogens, enzymes and other signalling molecules [12-15]. Decorin is classified as a small PG with a core protein of about $36 \mathrm{kDa}$ monosubstituted by a dermatan sulfate chain, and a defective glycosylation of this PG is involved in the progeroid variant of EDS [5, 6]. Recently, structural alteration of heparan sulfate chains has also been described and associated with the altered wound repair phenotype of EDS patients [16].

GAG chain initiation begins with the formation of a tetrasaccharide linkage region (GlcA $\beta 1$ $3 \mathrm{Gal} \beta 1-3 \mathrm{Gal} \beta 1-4 \mathrm{Xyl} \beta 1$ ) bound via the xylosyl residue to serines of the core protein [17]. The biosynthesis of this region is catalyzed, step by step, by distinct glycosyltransferases expressed in Golgi. From this linker tetrasaccharide, the sugar chains are extended by addition of two alternating monosaccharides, an aminosugar and a glucuronic acid [18]. The reaction leads to the formation of heparin and heparan-sulfate (HP/HS) when the aminosugar is $\mathrm{N}$ acetyl-glucosamine, and to chondroitin-sulfate and dermatan-sulfate (CS/DS) when it is $\mathrm{N}$ acetyl-galactosamine. The progeroid variant of EDS is caused by defects in the $\beta 1,4-$ galactosyltransferase 7 ( $\beta 1,4$-galT7), which catalyzes the transfer of the first galactose residue to the xylose of the tetrasaccharide linkage region $[2,3]$. Patients with the autosomal recessive progeroid variant of EDS present mutations in the coding sequence of the $\beta 4 G A L T 7$ gene. To date, from these patients, three mutations of the $\beta 4 \mathrm{GALT} 7$ gene corresponding to A186D, L206P and R270C substitutions have been identified [4, 19-21] which were associated with either reduction or loss of activity. However, the structural bases of these changes remain to be elucidated although a three-dimensional structure of the catalytic domain of the $\beta 1,4-$ GalT7 from drosophila in the presence of UDP has been recently solved [22]. Having access to the kinetic parameters (i.e., $k_{\text {cat }}$ and $K_{\mathrm{m}}$ ) values brings information but should be associated with access to thermodynamic parameters of substrate binding in order to interpret the consequences of the amino acid substitutions. Recently, we have validated isothermal titration calorimetry (ITC) method as a tool for detecting and quantifying the interactions between the substrates and the binding sites of the wild-type $\beta 1,4-G a l T 7$ [23].

In the present study, mutated $\beta 1,4-G a l T s 7$ were expressed as soluble maltose-binding fusion proteins in which the $N$-terminal cytoplasmic domain, the transmembrane segment and the stem region that precede the catalytic domain and correspond to amino acids 1-81 were deleted. The kinetic parameters and the thermodynamic parameters of all the mutated $\beta 1,4-$ GalTs7 were determined. The consequences of the mutations were also investigated ex vivo by evaluating the priming efficiency of xylosides on glycosaminoglycan chain initiation. 


\section{MATERIALS AND METHODS}

Cloning and expression of human $\beta 1,4-$ galactosyltransferases 7 in CHO618 cells [24]

The human $\beta 1,4-$ GalT7 sequence fused with a c-myc-tag was subcloned into pcDNA3.1 (Invitrogen, Cergy Pontoise, France) as previously described [23]. The pcDNA- $\beta 1,4-G a l T 7$ was then used as a template to construct the expression plasmids pcDNA-A186D, -L206P and -R270C by site-directed mutagenesis using the QuickChange site-directed mutagenesis kit (Stratagene, La Jolla, CA).

To express membrane proteins, $\beta 1,4$-galactosyltransferase7-deficient $\mathrm{CHO618}$ cells (ATCC number CRL2241) [24] were cultured in complete Dubelcco's modified Eagle's medium-F12 (Gibco, Cergy Pontoise, France) supplemented with fetal bovine serum (10\%), glutamine $(1 \mathrm{mM})$ and penicillin-streptomycin $(1 \%)$. The pcDNA expression plasmids $(10 \mu \mathrm{g})$ were transfected into CHO618 cells on $100 \mathrm{~mm}$ plates using Exgen 500 (Euromedex, Souffelweyersheim, France) according to the manufacturer's recommendations. Two days after transfection, cells were harvested and resuspended in Hepes-sucrose buffer $(5 \mathrm{mM}$ Hepes, $0.25 \mathrm{M}$ sucrose, $\mathrm{pH} 7.4$ ) and briefly sonicated (1 x $5 \mathrm{~s}$ ). Protein concentration of the resulting membrane fraction was determined by the method of Bradford [25]. The expression level of the wild type, A186D, L206P, L206A and R270C $\beta 1,4-G a l T 7 m y c$ proteins was evaluated by western blot analysis using anti-myc antibodies (Invitrogen, Cergy Pontoise, France) according to the manufacturer's recommendations. Quantification of $\beta 1,4-G a l T 7 m y c$ proteins was performed by densitometry using a scanner employing NIH Image software.

\section{Cloning, expression and purification of soluble forms of the human MBP-p1,4- galactosyltransferases 7}

Human $\beta 1,4-$ GalTs 7 were expressed as maltose-binding (MBP) fused proteins. To express the entire protein fused with the MBP, the $\beta 1,4-G a 1 T 7$ sequence was subcloned into the expression vector pMALc2x (New England Biolabs, Saint Quentin en Yvelines, France) and used as a template to construct the pMALc $2 \mathrm{x}-\mathrm{L} 206 \mathrm{P}_{\mathrm{aa} 1}$ expression plasmid by site-directed mutagenesis, as previously described. To express the soluble catalytic domain of $\beta 1,4-\mathrm{GalT} 7$, a truncated form of the $\beta 1,4-G a l T 7$ DNA sequence in which the nucleotides encoding the first $N$-terminal 81 amino acids are deleted was subcloned into pMALc2x, as previously described [23] and thus used as a template to construct the expression plasmids pMALc2x-A186 $\mathrm{D}_{\mathrm{aa} 82}$, $\mathrm{L}_{206 \mathrm{P}_{\mathrm{aa} 82}}$ and $-\mathrm{R}_{270 \mathrm{C}_{\mathrm{a} 82}}$ by site-directed mutagenesis. The expression of soluble fused MBP-proteins in E. coli BL21(DE3) cells (Invitrogen, Cergy Pontoise, France) and the purification onto an amylose column were performed as described previously [23]. The concentration of the purified fusion proteins was determined by fluorescence using a 2100 Bioanalyser (Agilent, Massy, France), according to the manufacturer's recommendations.

\section{及1,4-galactosyltransferase activity}

$\beta 1,4$-galactosyltransferase activity were determined as described previously [23] in the presence of 15 to $30 \mu \mathrm{g}$ of total proteins containing membrane $\beta 1,4-G a l T 7$ (i.e., 0.3 to $0.6 \mathrm{~g}$ of total proteins..$^{-1}$ ) or 2 to $10 \mathrm{pmol}$ of purified truncated $\beta 1,4$-GalT7 (i.e., 0.04 to $0.2 \mu \mathrm{M}$ ), and various concentrations of $4 \mathrm{MU}-\mathrm{Xyl}$ or $\mathrm{pNP}-\mathrm{Xyl}$ (i.e., 0.02 to $10 \mathrm{mM}$ of $4 \mathrm{MU}-\mathrm{Xyl}$ or pNP-Xyl in the presence of $10 \mathrm{mM}$ of UDP-Gal) and UDP-Gal (i.e.,0.025 to $20 \mathrm{mM}$ of UDP-Gal in the presence of $10 \mathrm{mM}$ of $4 \mathrm{MU}-\mathrm{Xyl}$ or $\mathrm{pNP}-\mathrm{Xyl}$ ). The estimation of the kinetic parameters was achieved by the incubation of at least 10 different concentrations of substrate. Incubations were performed in duplicates. Data were fitted by non-linear regression to the MichaelisMenten model using the curvefitter program of Sigmaplot $9.0^{\mathrm{Tm}}$.

\section{Reaction products characterisation}


The characterization of the purified reaction products obtained after glycosylation of 4MU$\mathrm{Xyl}$ in the presence of saturating concentration of UDP-Gal by MBP-truncated wild-type, A186D, L206P and R270C $\beta 1,4-G a l T s 7$ (i.e., deleted of the amino acids 1-81) was performed by NMR analysis, as described previously [23].

\section{Isothermal titration calorimetry}

ITC experiments were carried out as described previously [23]. UDP (0.5 to $1 \mathrm{mM})$ and pNP$\mathrm{Xyl}(40 \mathrm{mM})$ were used as donor and acceptor substrate analogues, respectively. Ligand solutions were diluted in the final dialysis used for the protein to achieve the expected final concentration (UDP, 0.5 to $1 \mathrm{mM}$; pNP-Xyl, $40 \mathrm{mM}$ ) and, injected (35 injections of 4 to 10 $\mu \mathrm{l})$ into the reaction cell containing the degassed purified MBP-truncated-fused proteins (i.e., lacking the $N$-terminal amino acids $1-81)(1.4 \mathrm{ml}, 30$ to $50 \mu \mathrm{M})$. Thermodynamic parameters of the binding of the ligands to the proteins were obtained from individual experiments with three different batches of purified MBP-proteins and for each batch, determination was performed in duplicate. Thermodynamic parameters $n$ (stoichiometry), $\Delta H$ (enthalpy change) and $K_{a}$ (association constant) were obtained by non-linear least-squares fitting of experimental data using the single-site model of the Origin 7.0 software package provided with the instrument. The dissociation constant $\left(K_{\mathrm{d}}\right)$, the free energy of binding $(\Delta G)$ and entropy change $(\Delta S)$ were deduced from the $K_{a}$ and $\Delta H$ values.

\section{Labelling and Isolation of Radioactive GAGs}

Metabolic labelling of GAGs with $\left[{ }^{35} \mathrm{~S}\right]$ was performed using a modification of a previously published procedure [24]. Cells were incubated with or without $4 \mathrm{MU}-\mathrm{Xyl}(0$ to $1 \mu \mathrm{M})$ for 9 hours in sulfate-free medium (Gibco, Cergy Pontoise, France) containing $10 \mu \mathrm{Ci} / \mathrm{mL}$ $\mathrm{Na}_{2}\left[{ }^{35} \mathrm{~S}_{\mathrm{SO}_{4}}\right.$ (Perkin Elmer Life Sciences, Courtaboeuf, France). GAGs were isolated from the medium using a modification of a previously published procedure [26].

Medium was harvested and digested by papain buffer $(20 \mathrm{mM}$ sodium phosphate $\mathrm{pH} 6.8$ containing $1 \mathrm{mM}$ ethylenediamine tetraacetic acid, $5 \mathrm{mM} L$-cysteine hydrochloride and $1 \mathrm{~g} . \mathrm{L}^{-}$ ${ }^{1}$ papain) for 2 hours at $60^{\circ} \mathrm{C}$. After boiling and centrifugation, supernatant was precipitated overnight at $4^{\circ} \mathrm{C}$ with 3 volumes of potassium acetate (in 5\% ethanol). After centrifugation, pellet was resuspended in $0.2 \mathrm{M} \mathrm{NaCl}$ and then centrifuged. Supernatant was supplemented by $100 \mu \mathrm{g}$ of chondroitin sulfate from shark cartilage (Sigma) and $5 \%$ acetylpyridinium chloride (Sigma) and then incubated for 2 hours at $37^{\circ} \mathrm{C}$ before centrifugation. After washing twice with $\mathrm{NaCl}(0.2 \mathrm{M}$, then $2.5 \mathrm{M})$, GAGs were resuspended in $0.2 \mathrm{M}$ Tris- $\mathrm{HCl}(\mathrm{pH} 8.0)$ and the radioactivity associated was counted with $4.5 \mathrm{ml}$ of liquid scintillation counting cocktail Ultima-Gold (Perkin Elmer Life Sciences).

\section{RESULTS}

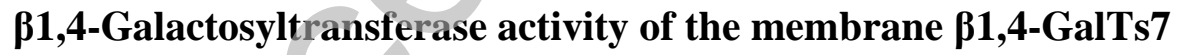

To address the in vivo consequences of the mutations on the enzyme function, membrane wild-type, A186D, L206P, L206A and R270C $\beta 1,4-G a l T s 7$ were overexpressed in CHO618 cells. Overexpression of each recombinant protein in membrane fractions was demonstrated by western blot using anti-myc antibodies. All were expressed with an expected molecular mass of approximately $37 \mathrm{kDa}$. The expression level of wild-type, A186D, L206P L206A and R270C $\beta 1,4-G a l T s 7$ quantified by densitometry was similar, allowing the determination and the comparison of specific activities at saturating concentrations of 4MU-Xyl and UDP-Gal (referred to as $k_{\text {obs }}$ and expressed as nmol of products formed. $\mathrm{mg}^{-1}$ of total protein. $\mathrm{min}^{-1}$ ).

The ability of each membrane protein to catalyze the transfer of galactose from donor (UDPGal) to acceptor (pNP-Xyl) substrate analogues was determined. No activity was detected with the membrane fraction containing the L206P $\beta 1,4-G a l T 7$. The membrane fraction 
containing the wild-type $\beta 1,4-G a l T 7$, but also the A186D, L206A and R270C $\beta 1,4-$ GalTs7 were active. As shown in Table 1 , the $K_{\mathrm{m}}$ values of UDP-Gal for membrane A186D and R270C $\beta 1,4-G a l T s 7$ were 8- and 2-fold higher than that for wild type, respectively, whereas no difference was observed for L206A mutant. The $K_{\mathrm{m}}$ values of pNP-Xyl for A186D, L206A and R270C $\beta 1,4-G a l T s 7$ were 4-, 2.6- and 6-fold higher than that for the wild type, respectively. Finally, the $k_{\text {obs }}$ values for A186D and R270C $\beta 1,4-G a l T s 7$ were 3- and 1.5-fold lower compared to the wild type, respectively whereas no difference was observed for the L206A mutant.

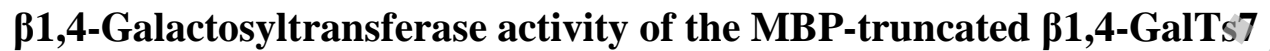

In order to determine the molecular bases of the reduced activity of A186D and R270C $\beta 1,4-$ GalTs7, and of the loss of activity of L206P $\beta 1,4-G a l T 7$, mutated $\beta 1,4-G a l$ Ts 7 were expressed and purified as soluble MBP-truncated proteins, as previously performed for the wild-type enzyme [23]. The purified MBP- R270C $\mathrm{aa82}_{\text {(Figure 2, lane 1) and MBP-WT }}$ a82 (Figure 2, lane 4) migrated as a single band, with an apparent molecular weight of $70 \mathrm{kDa}$, consistent with the calculated molecular mass of the truncated $\beta 1,4-G a l T 7$ fused with the

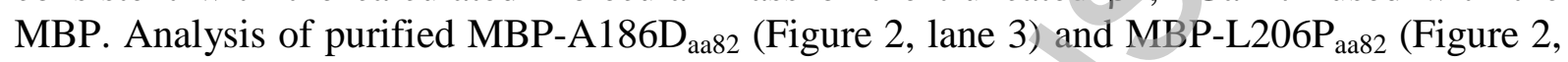
lane 2) revealed the presence of a major band ( $65 \%$ and $90 \%$ of purity, respectively) with the same electrophoretic mobility as the MBP-WT $\mathrm{Wa}_{\mathrm{a} 2}$, along with several other bands with lower molecular weight. These additional bands were probably due to proteolysis, as they were also recognized by anti-MBP antibodies (data not shown).

As previously shown [23], MBP-WT ${ }_{\mathrm{aa} 82}$ can transfer the galactose residue from UDP-Gal to $\beta$-xylosides with $K_{\mathrm{m}}$ values for UDP-Gal, pNP-Xyl and $4 \mathrm{MU}-\mathrm{Xyl}$ (i.e., $0.23 \mathrm{mM}, 1.27 \mathrm{mM}$ and $0.27 \mathrm{mM}$, respectively) (Table 2) similar to those of the membrane wild-type $\beta 1,4-\mathrm{GalT} 7$ (i.e., $0.29,0.85$ and $0.24 \mathrm{mM}$, respectively). MBP-A186D $\mathrm{D}_{\mathrm{a} 82}$ and MBP-R270C $\mathrm{C}_{\mathrm{a} 82}$ were also able to transfer galactose from UDP-Gal to both acceptor substrates, pNP-Xyl and 4MU-Xyl. Structural characterization of the reaction products by NMR analysis showed that MBP$\mathrm{A}_{186 \mathrm{D}_{\mathrm{a} 82}}$ and MBP-R270C $\mathrm{C}_{\mathrm{a} 82}$ formed the same $\beta 1 \rightarrow 4$ linkage as $\mathrm{MBP}-\mathrm{WT}_{\mathrm{aa} 82}$ between the Gal from UDP-Gal donor substrate and the Xyl from the acceptor substrate in the reaction product (data not shown). The $K_{\mathrm{m}}$ values of UDP-Gal and pNP-Xyl for MBP-A186D aa82 were

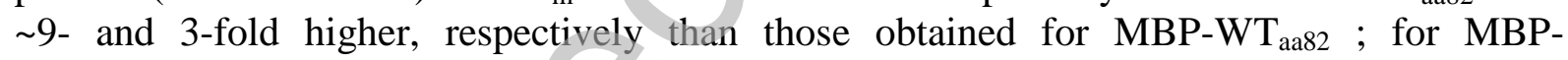
$\mathrm{R} 270 \mathrm{C}_{\mathrm{aa} 82}, K_{\mathrm{m}}$ values were $\sim 3$ - and 6-fold higher (Table 2). These increases in $K_{\mathrm{m}}$ values were similar to those observed for the corresponding membrane proteins (for A186D mutant, 8and 5-fold higher towards UDP-Gal and pNP-Xyl, respectively; for R270C mutant, 2 and 6fold higher). On the other hand, the $k_{\text {cat }}$ values measured for the reaction catalyzed by MBP$\mathrm{A}_{186 \mathrm{D}_{\text {aa82 }} \text { and MBP-R270C }}$ aa82 were similar to MBP-WT $\mathrm{Ma}_{\text {a82 }}$ (Table 2).

MBP-L206 $\mathrm{P}_{\mathrm{a} a 82}$, contrary to membrane L206P $\beta 1,4-\mathrm{GalT7}$ which displayed no activity, was able to transfer galactose residue from UDP-Gal to acceptor substrate generating the same $\beta 1 \rightarrow 4$ linkage product as wild-type $\beta 1,4-G a l T 7$ (data not shown). The $K_{\mathrm{m}}$ values of UDP-Gal and pNP-Xyl were $\sim 3$ - and 4-fold higher, respectively than those obtained for MBP-WT $\mathrm{Ta}_{\text {a82 }}$. The $k_{\text {cat }}$ value of MBP-L206P aa82 was similar to that of $\operatorname{MBP}_{-W T}$ aa82 (i.e., $60 \mathrm{~min}^{-1}$ ) (Table 2). Because of the partial purity of MBP-L206P $\mathrm{P}_{\text {aa82 }}$, the $k_{\text {cat }}$ value determined for MBP-L206P $\mathrm{P}_{\text {aa82 }}$ was certainly underestimated and rather corresponded to a value of $\sim 100 \mathrm{~min}^{-1}$, assuming a purity of $\sim 65 \%$.

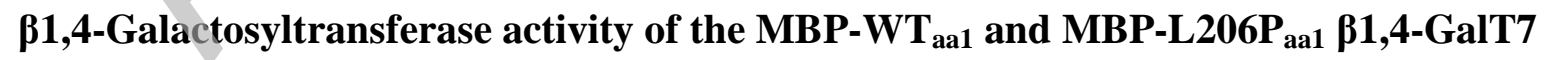
To better understand why L206P substitution led to loss of activity for membrane L206P $\beta 1,4-G a l T 7$ while MBP-truncated L206P $\beta 1,4-G a l T 7$ was active, the entire $\beta 1,4-G a l T 7$ (from amino acids 1 to 327) and the corresponding L206P $\beta 1,4-G a l T 7$, both fused with MBP, were produced in E. coli and purified, as previously described. SDS-PAGE analysis of purified 
MBP-WT $_{\text {aal }}$ (Figure 2, lane 6) and MBP-L206P $\mathrm{P}_{\mathrm{aa} 1}$ (Figure 2, lane 5) revealed the presence of a major band with an apparent molecular weight of $85 \mathrm{kDa}$. As reported previously, many other bands with lower molecular weight and recognized by anti-MBP antibodies were also visible, suggesting a significant proteolysis of these recombinant proteins.

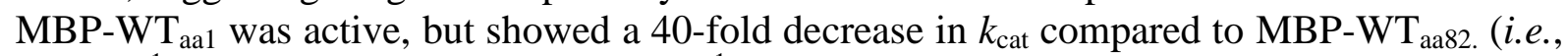

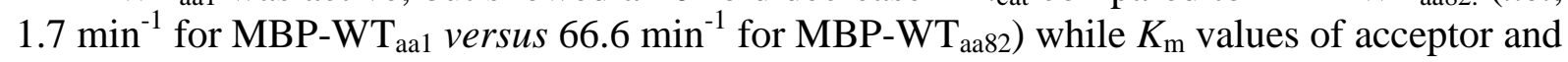
donor substrates were increased by a factor of 4 and 3 , respectively. The reason why the activity decreases when the $N$-terminal part 1-81 is inserted between MBP and the catalytic domain remains to be determined. Contrary to $\mathrm{MBP}^{-\mathrm{WT}_{\mathrm{aa} 1} \text { and MBP-L206P }}$ aa82, no detectable

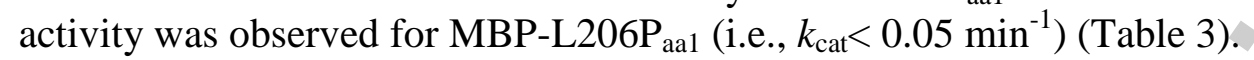

\section{Thermodynamic characterization of the substrate binding to MBP-A186D a 82 and MBP- $\mathbf{R 2 7 0 C}_{\text {aa82 }}$}

As shown from the comparison of the $K_{\mathrm{m}}$ values of the acceptor and donor substrates for wildtype and mutant $\beta 1,4-$ GalTs7, A186D and R270C substitutions lead to increase of the $K_{\mathrm{m}}$ values of both substrates. It is therefore difficult to conclude with certainty whether Ala-186 and Arg-270 contribute to the donor or the acceptor sites, and thus to interpret the consequences of the substitutions at the structural level. Consequently, the thermodynamic parameters of the binding of donor and acceptor substrates to MBP-A $186 \mathrm{D}_{\mathrm{aa} 82}$ and MBP$\mathrm{R}_{270 \mathrm{C}_{\mathrm{a} 82}}$ comparatively to MBP-WT $\mathrm{aa}_{22}$ were explored by ITC. Exothermic binding profiles were obtained with all the purified proteins. Typical calorimetric profiles of the binding substrates analogues to MBP-WT $\mathrm{Ta}_{\mathrm{a} 2}$ and MBP-A186D $\mathrm{D}_{\mathrm{a} 82}$ are presented in Figure 3. Similar profiles were obtained for the MBP-R270C $\mathrm{aa}_{\mathrm{a} 22}$.

Whatever the mutated enzyme, the stoichiometry of UDP binding was comprised between 0.4 to 0.6 , due to the possible dimeric state of the enzyme, as described previously [23]. The binding of donor substrate analogue to wild-type, A186D and R270C $\beta 1,4-G a l T s 7$ was driven by an enthalpy change, which was partially counterbalanced by an unfavourable entropy change (Table 4). Binding of UDP to MBP-R270C $\mathrm{C}_{\mathrm{a} 82}$ showed similar thermodynamic parameters as MBP-WT $\mathrm{Wa}_{\mathrm{a} 2}$, suggesting no modification of UDP binding by the R270C substitution (Table 4). On the contrary, binding of UDP to the enzyme was significantly modified by the substitution of Ala 186 residue by Asp (Figure 3A), with a significant decrease of $\Delta H$ that was not fully offset by a decrease in $\Delta S$. Therefore, dissociation constant was 4-fold higher to that of MBP-WT $\mathrm{Wa}_{\mathrm{a} 2}$ (Table 4).

Similarly, the consequences of the A186D and R270C substitutions for the binding of acceptor substrate (pNP-Xyl) to the $\beta 1,4-G a l T 7$ were analyzed by ITC (Figure 3B). The pNP$\mathrm{Xyl}$ substrate was used because of the limited solubility of 4MU-Xyl. Because UDP is required to promote the binding of the acceptor substrate to the enzyme, we explored the binding of pNP-Xyl in the presence of UDP and $\mathrm{Mn}^{2+}$, as previously described [23]. Since the $K_{\mathrm{d}}$ value obtained for the binding of pNP-Xyl to the wild type was higher than the protein concentration, the $\mathrm{c}$-value $\left(\mathrm{c}=[\mathrm{Prot}]_{\mathrm{t}} / \mathrm{K}_{\mathrm{d}}\right.$ ) was lower than 1 . Under low c-value conditions, both $\Delta G$ and $\Delta H$ can be measured with confidence provided that, at least, $80 \%$ saturation is achieved and that the stoichiometry $n$ is known, as described by Turnbull and Danaras [27]. For MBP-WT $\mathrm{aa}_{22}$ and MBP-A186D $\mathrm{aa}_{22}$, but not for MBP-R270 $\mathrm{aa}_{22}$, it was possible to reach saturating ligand concentration. Therefore, we used the stoichiometry value determined independently by the active site titration experiments with UDP under higher $c$-values conditions, for fitting the low c-value titrations. Consequently, a dissociation constant of 4.6 $\mathrm{mM}$ was measured for the binding of pNP-Xyl to MBP-WT $\mathrm{Wa}_{\mathrm{a} 2}$ (Table 5). Its binding to MBP$\mathrm{WT}_{\mathrm{a}} 82$ was driven by an enthalpy change $(-11.8 \mathrm{kcal} / \mathrm{mol})$ with an unfavourable entropy change. Binding of pNP-Xyl to MBP-A $186 \mathrm{D}_{\mathrm{aa} 82}$ was relatively similar to that of MBP$\mathrm{WT}_{\mathrm{a} a 82}$, with an estimated dissociation constant of about $5.8 \mathrm{mM}$ (Figure 3B). The magnitude 
of $\Delta H$ was higher (by about $13 \mathrm{kcal} / \mathrm{mol}$ ) than that obtained for MBP-WT $\mathrm{Ma}_{\mathrm{a} 22}$, yet fully offset by an equivalent increase in entropy, resulting in a similar affinity as the wild type. Contrary to MBP-A186D $\mathrm{D}_{\mathrm{a} 82}$, the binding of pNP-Xyl to MBP-R270C $\mathrm{aa}_{\mathrm{a} 2}$ was difficult to detect by ITC and the saturation was not reached, preventing an accurate determination of the thermodynamic parameters. Nevertheless, the estimated binding affinity seemed to be very weak $\left(K_{\mathrm{d}}>10 \mathrm{mM}\right)$.

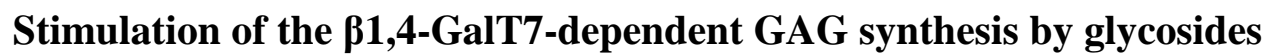

To identify the consequence of the mutations on the GAG synthesis, we overexpressed membrane wild-type, A186D, L206P and R270C $\beta 1,4-G a 1 T s 7$ in CHO618 cells and evaluated the GAG synthesis level after transfection. Immunoblot analysis showed that all $\beta 1,4-G a l T s 7$ were produced at similar level (as shown in Figure 1). Analysis of the GAG synthesis rate $48 \mathrm{~h}$ after transfection led to a 4-fold increase of ${ }^{35} \mathrm{~S}$-incorporation compared to mocktransfected cells (Figure 4), indicating that overexpression of $\beta 1,4-G a l T 7$ significantly enhanced GAG synthesis. Surprisingly, overexpression of A186D or R270C $\beta 1,4-G a l T 7$ stimulated GAG synthesis at the same level as wild-type $\beta 1,4-G a 1 T 7$. Only L206P $\beta 1,4-$ GalT7 failed to increase GAG synthesis, with a rate similar to that of mock-transfected cells (Figure 4).

To further understand the consequences of the A186D and R270C substitutions on GAG synthesis, we investigated the ability of $4 \mathrm{MU}-\mathrm{Xyl}$ to prime the $\beta 1,4-\mathrm{GalT} 7$-dependent GAG synthesis in $\mathrm{CHO618}$ cells after transfection by pcDNA- $\beta 1,4-G a l T 7$ s. Two days after transfection, cells were incubated for 9 hours with $4 \mathrm{MU}-\mathrm{Xyl}$, and the ability of glycoside to prime GAG synthesis in transfected cells was evaluated. Kinetics of GAG synthesis stimulation by $4 \mathrm{MU}-\mathrm{Xyl}$ (from 0 to $1 \mu \mathrm{M}$ ) in $\mathrm{CHO618}$ cells transfected by pcDNA- $\beta 1,4-$ GalT7s are presented in Figure 5. Stimulation of GAG synthesis was not observed in CHO618 cells transfected by pcDNA-L206P, whatever the 4MU-Xyl concentration. In CHO618 cells transfected by pcDNA- $\beta 1,4-$ GalT7, -A186D and -R270C, GAG synthesis stimulation was a linear function of $4 \mathrm{MU}-\mathrm{Xyl}$ concentration. However, the GAG synthesis was less stimulated in $\mathrm{CHO618}$ cells transfected by pcDNA-A186D and -R270C. Therefore, we determined the slope of the linear regression which was representative of the GAG synthesis stimulation. In cells transfected with pcDNA- $\beta 1,4-G a l T 7$, the slope was 0.04 . In cells transfected with pcDNA-A186D and -R270C, slopes markedly decreased to 0.03 and 0.02 , respectively.

\section{DISCUSSION}

$\beta 1,4-G a l T 7$ catalyses a limiting step in the biosynthesis of GAG chains [28, 29]. Patients with mutation in $\beta 4 G A L T 7$ gene suffer from skin, cartilage and bone alterations [2]. Only three mutations of the $\beta 4 G A L T 7$ gene (A186D, L206P and R270C) have been so far identified [4, 19-21], but leading only to two different genotypes (i.e., compound heterozygosity for the A186D and L206P ; homozygosity for the R270C) [4, 19-20]. Surprisingly, whatever the genotype, patients with the progeroid variant of EDS showed the same premature aging phenotype. The aim of this work was to elucidate the biochemical and structural consequences of the $\beta 4 G A L T 7$ mutations on the enzyme function using ITC as a method of choice for probing interactions at the substrate-binding sites of the enzyme [23, 3032].

Because the wild-type $\beta 1,4-G a l T 7$ catalytic domain (from amino acid 82 to the end of the protein) fused with the MBP is highly soluble and shows $K_{\mathrm{m}}$ values identical to those of the membrane wild-type $\beta 1,4-G a l T 7$ [23], we decided to express in the current study the catalytic domain of the mutated proteins fused with MBP. However, before exploring the physicochemical properties of the MBP-fused truncated enzymes, we systematically 
compared by kinetic analysis their ability to transfer the galactose residue from UDP-Gal to acceptor substrate analogue to that of the corresponding enzyme expressed in Golgi membranes of eucaryotic cells.

The MBP-A186D $\mathrm{D}_{\mathrm{a} 82}$ is able to transfer galactose residue from UDP-Gal to acceptor substrate by generating the same $\beta 1 \rightarrow 4$ linkage product as wild-type $\beta 1,4-G a l T 7$ (shown as in reference 23). However, the catalytic efficiencies of MBP-A186D aa82 with UDP-Gal donor and 4MU-Xyl and pNP-Xyl acceptors are 10, 10 and 4-fold lower, respectively, than those of MBP-WT ${ }_{\text {aa82 }}$, due to higher $K_{\mathrm{m}}$ values. Almeida et al [19] also reported an increase of the $K_{\mathrm{m}}$ value for the donor substrate (4 fold higher), whereas no significant change was observed for the binding of the acceptor substrate. The ITC results clearly demonstrate that MBPA186D $\mathrm{D}_{\mathrm{a} 82}$ was able to bind donor and acceptor substrate analogues. But, the $K_{\mathrm{d}}$ value of UDP for MBP-A186D $\mathrm{D}_{\mathrm{a} 82}$ was 4-fold higher than that of wild type, while that of pNP-Xyl was similar to the wild type. These results suggest that Ala 186 contributes directly or, more probably, indirectly to the binding donor site [22]. Interestingly, the $\Delta H$ for the binding of UDP to MBP-A186D aa82 was significantly reduced by about $15 \mathrm{kcal} \mathrm{mol}^{-1}$ compared to wild type. In our recent study, a major contribution of the $\beta$-phosphate, and more moderately the $\alpha$ phosphate of the donor substrate to the binding to $\beta 1,4-G a l T 7$ was demonstrated [23]. Therefore, the carboxyl side chain of Asp-186 in MBP-A186D aa82 could induce repulsive interactions with the phosphate groups of UDP, and prevents the formation of a network of interactions between the donor substrate analogue and the protein. However, Ala-186 which is located in the hydrophobic core of the enzyme and surrounded by bulky aromatic residues $[22,33]$ likely is not essential in binding UDP in the wild type. This is also in accordance with the fact that Ala-186 corresponds to Ser-274 in $\beta 1,4-G a l T 1$, an uncharged hydrophilic residue, capable of forming hydrogen bonds instead of hydrophobic [19].

Concerning the R270C substitution, few biochemical information is currently available. This substitution was previously reported to decrease by approximately 3 -fold the $\beta 1,4$-galactosyltransferase activity in $\beta 1,4-$ GalT7 R270C fibroblasts compared to control fibroblasts [6]. Herein, MBP-R270C $\mathrm{C}_{\mathrm{aa} 82}$ was active, but the $k_{\mathrm{cat}} / K_{\mathrm{m}}$ ratio determined towards 4MU-Xyl was particularly affected (11-fold lower compared to wild type) due to higher $K_{\mathrm{m}}$ value, whereas that towards UDP-Gal was almost similar to the wild type. The ITC results clearly demonstrate that Arg-270 does not interact directly with the donor substrate analogue, as MBP-R270C $\mathrm{Ca}_{\mathrm{a} 82}$ was unaffected for UDP binding. On the contrary, the binding of acceptor substrate analogue to MBP- $270 \mathrm{C}_{\mathrm{aa} 82}$ was particularly modified and the binding isotherm did not reach saturation, preventing accurate determination of thermodynamic parameters of binding. The drastic loss of pNP-Xyl binding by MBP-R270C $\mathrm{C}_{\mathrm{aa} 2}$ suggests that this positively charged residue is critical for acceptor substrate binding. In the absence of a 3D-structure of the complex $\beta 1,4-G a l T 7 / a c c e p t o r$ substrate, it is difficult to explain the requirement of Arg270 residue in the binding of acceptor substrate. Sequence comparison of human $\beta 1,4-$ galactosyltransferase family members showed sequence variations in their oligosaccharide binding site, which would account for their respective preferences for different oligosaccharides $[34,35]$. We suggest that Arg-270 residue which is a lysine residue in the Drosophila enzyme [22], and is located on a flexible loop, may interact directly with acceptor substrate by salt bridge or hydrogen bonding interactions or may be a structural element in the organization of the acceptor active site.

Substitution of Leu-206 by Pro was previously reported to inactivate the enzyme [19, 20]. In these studies, L206P $\beta 1,4-G a l T 7$ was expressed either as a truncated protein lacking the first $N$-terminal 53 amino acids fused to protein A [20] or as a secreted form lacking the first $N$-terminal 63 amino-acids. Similar results were found in our study when the full length L206P protein was expressed either as a membrane protein or as a soluble protein fused with the MBP. As shown from the amino-acid alignment, Leu-206 is conserved in all mammalian 
11,4-GalTs7 and in the related Caenhorabditis Elegans sqv-3 [36], while it is a valine residue in the Drosophila enzyme [22]. The Leu-206 or its equivalent Val is located in the hydrophobic core of the protein $[22,37]$. Therefore, due to the location of Leu-206 and the fact that the L206A mutant shows kinetic parameters similar to the wild type, Leu-206 has probably no role in the catalytic efficiency of the enzyme. As suggested by Almeida et al. [19] and Okajima et al.[20], Pro substitution at position 206 could drastically change the structure of the protein, and therefore would be responsible for the loss of activity. In our study, however, when L206P $\beta 1,4-G a l T 7$ was expressed as a fusion MBP protein, deleted of the first $N$-terminal 81 amino acids, a catalytic activity as efficient as that of its wild-type counterpart was observed. Such a result indicates that substitution of Leu-206 by Pro does not modify the fold of the catalytic domain, at least under a $\beta 1,4-$ GalT7 form in which the $N$ terminal cytoplasmic domain, the transmembrane segment and the stem region which precedes the catalytic domain have been deleted. Therefore, our results, combined with those of Okajima et al. which showed that L206P $\beta 1,4-G a l T 7$ fused to protein A and in which only the stem is present, is inactive [20] suggest that it is the combination of both the Pro residue at position 206 and at least the stem which leads to loss of activity due likely to a modification of the conformation of the protein and in return of the active site.

Similar clinical symptoms and aberrant GAG substitution of PGs were observed in patients with compound heterozygosity for the A186D and L206P and patients with homozygosity for the R270C [5, 6, 16, 19]. Nevertheless, molecular consequences of the three reported substitutions of the $\beta 1,4-G a l T 7$ identified in EDS patients on the enzyme function are clearly different. L206P $\beta 1,4-G a l T 7$ is inactive due to altered conformation or altered substrates binding, and overexpression of L206P $\beta 1,4-G a l T 7$ in $C H O 618$ cells is unable to synthesise GAG chains. In contrast, A186D and R270C $\beta 1,4-G a l T 7 s$ display activity. However, A186D and R270C substitutions lead to a decrease of the $\beta 1,4-G a l T 7$ efficiency due to a lowered binding of donor substrate and acceptor substrate, respectively. In our study, the measurement of the ${ }^{35} \mathrm{~S}$ incorporation into $\mathrm{GAG}$, reflecting their biosynthesis rate, was surprisingly similar in wild-type, A186D or R270C $\beta 1,4-G a l T 7$-transfected CHO618 cells. Therefore, evaluation of the ability of each mutated protein to prime ex vivo the GAG biosynthesis was carried out. Since the requirement for xylosylated core proteins can be bypassed by synthetic $\beta$-D-xylosides containing hydrophobic aglycones [38-40], we used $4 \mathrm{MU}-\mathrm{Xyl}$ as a primer for GAG formation. Priming by $\beta$-D-xylosides depended linearly on 4MU-Xyl concentration, sugggesting that the acceptor substrate (i.e., the xylosylated-core protein) is a limiting factor of the GAG synthesis. In wild type-transfected cells, stimulation of GAG synthesis was 10 -fold higher when $1 \mu \mathrm{M}$ of $4 \mathrm{MU}-\mathrm{Xyl}$ was used compared to the condition without glycoside; it was 9- and 6-fold, in A186D- and R270C-transfected cells, respectively. The ability of A186D $\beta 1,4-G a l T 7$ to prime GAG synthesis was thus weakly affected compared to that of wild-type enzyme. If we consider that the availability of acceptor substrate is a limiting factor of GAG synthesis, this result is consistent with the ability of A186D $\beta 1,4-G a l T 7$ to bind the acceptor substrate. CHO618 cells stably expressing A186D $\beta 1,4-G a l T 7$ were also described to be able of substituting human decorin with GAG chains, however with a considerably decreased efficiency [5]. Because of the limited consequences of the A186D substitution on the GAG synthesis, it would be interesting to know the phenotype of homozygous for A186D in that respect. Only the phenotype of individuals with compound heterozygosity for A186D and L206P is known. Because L206P $\beta 1,4-G a l T 7$ is inactive, this phenotype is certainly essentially associated to the L206P mutation of the $\beta 1,4-G a l T 7$. Moreover, it is likely that homozygosity for L206P is not a viable genotype. Indeed, the transfer of the first galactose on the tetrasaccharide linker region of the GAG chains is strictly catalyzed by the $\beta 1,4-G a l T 7$ and cannot be bypassed by another glycosyltransferase [24]. Contrary to A186D $\beta 1,4-G a l T 7$, the ability of R270C $\beta 1,4-G a l T 7$ to prime GAG synthesis 
was largely affected compared to that of wild-type enzyme. This lower priming efficacy of 4MU-Xyl in the R270C $\beta 1,4-G a l T 7$ transfected $\mathrm{CHO618}$ cells may be due to the substitution of Arg-270 residue by Cys that modifies the binding affinity of the acceptor substrate. The reduced ability of the R270C $\beta 1,4-G a l T 7$ to prime GAG synthesis can explain the defective glycosylation of decorin and biglycan in homozygotic individuals for R270C $[6,16]$. On the other hand, in $\beta 1,4-G a l T 7$ R270C fibroblasts, a reduced epimerization of chondroitin/dermatan sulfate GAG chains [6] and a modified pattern of heparan sulphate chains [16] was observed. Thus, there is evidence that the $\beta 1,4-G a l T 7$ genetic defects, along with a decrease in the GAG biosynthesis rate, also affect the quality and diversity of the chains, via epimerization and sulfation reactions, and finally the biological function of these substances.

\section{FOOTNOTES}

This work was supported by grants from Agence Nationale pour la Recherche (NT053_42251). Grants from Region Lorraine, from Communauté Urbaine du Grand Nancy and from Conseil Général de Meurthe et Moselle were also gratefully acknowledged. ITC experiments on the VP-ITC apparatus were conducted in the "Service Commun de Biophysicochimie des Interactions Moléculaires" of the University Henri Poincaré, Nancy Université.

We would like to give our thanks to A. Kriznik (UMR CNRS-Nancy Université 7214) and O. Fabre (UMR CNRS-INPL 7568) for ITC and NMR technical support, respectively.

\section{REFERENCES}

1 Beighton, P., De Paepe, A., Steinmann, B., Tsipouras, P., and Wenstrup, R.J. (1998) Ehlers-Danlos syndromes: revised nosology, Villefranche, 1997. Ehlers-Danlos National Foundation (USA) and Ehlers-Danlos Support Group (UK). Am. J. Med. Genet. 77, 3137

2 Kresse, H., Rosthoj, S, Quentin, E, Hollmann, J, Glössl, J., Okada, S., and Tonnesen, T. (1987) Glycosaminoglycan-free small proteoglycan core protein is secreted by fibroblasts from a patient with a syndrome resembling progeroid. Am. J. Hum. Genet. 41, 436-453

3 Quentin, E., Gladen, A., Roden, L., and Kresse, H. (1990) A genetic defect in the biosynthesis of dermatan sulfate proteoglycan: galactosyltransferase I deficiency in fibroblasts from a patient with a progeroid syndrome. Proc. Natl. Acad. Sc.i U S A. 87, 1342-1346

4 Faiyaz-Ul-Haque, M., Zaidi, S.H., Al-Ali, M., Al-Mureikhi, M.S., Kennedy, S., AlThani, G., Tsui, L.C., and Teebi, A.S. (2004) A novel missense mutation in the galactosyltransferase-I (B4GALT7) gene in a family exhibiting facioskeletal anomalies and Ehlers-Danlos syndrome resembling the progeroid type. Am. J. Med. Genet. 128A, 39-45

5 Götte, M., and Kresse, H., (2005) Defective glycosaminoglycan substitution of decorin in a patient with progeroid syndrome is a direct consequence of two point mutations in the galactosyltransferase I (beta4GalT-7) gene. Biochem. Genet. 43, 65-77

6 Seidler, D.G., Fayaz-Ul-Haque, M., Hansen, U., Yip, G.W., Zaidi, S.H.E., Teebi, A.S., Kiesel, L., and Götte, M. (2006) Defective glycosylation of decorin and biglycan, altered collagen structure, and abnormal phenotype of the skin fibroblasts of an EhlersDanlos syndrome patient carrying the novel Arg270Cys substitution in galactosyltransferase I (beta4GalT-7). J. Mol. Med. 84, 583-594 
7 Ruoslahti, E. and Yamaguchi, Y. (1991) Proteoglycans as modulators of growth factor activities. Cell 64, 867-869

8 Bandtlow, C.E., and Zimmermann, D.R. (2000) Proteoglycans in the developing brain: new conceptual insights for old proteins. Physiol. Rev. 80, 1267-1290.

9 De Cat, B., and David, G. (2001) Developmental roles of the glypicans. Semin. Cell Dev. Biol. 12, 117-125

10 Knudson, C.B., and Knudson, W. (2001) Cartilage proteoglycans. Semin. Cell Dev. Biol. 12, 69-78

11 Rapraeger, A.C. (2001) Molecular interactions of syndecans during development. Semin. Cell Dev. Biol. 12, 107-116

12 Poole, A.R. (1986) Proteoglycans in health and disease: structures and functions. Biochem. J. 236, 1-14

13 Ruoslahti, E. (1989) Proteoglycans in cell regulation. J. Biol. Chem. 264, 13369-13372

14 Salmivirta, M., Lidholt, K., and Lindahl, U. (1996) Heparan sulfate: a piece of information. FASEB J. 10, 1270-1279

15 Taipale, J., and Keski-Oja, J. (1997) Growth factors in the extracellular matrix. FASEB J. 11, 51-59

16 Götte, M., Spillmann, D., Yip, G.W., Versteeg, E., Echtermeyer, F.G., Van Kuppevelt, T.H., and Kiesel, L. (2008) Changes in heparan sulfate are associated with delayed wound repair, altered cell migration, adhesion and contractility in the galactosyltransferase I (beta4GalT-7) deficient form of Ehlers-Danlos syndrome. Hum. Mol. Genet. 17, 996-1009

17 Esko, J.D. and Zhang, L. (1996) Influence of core protein sequence on glycosaminoglycan assembly. Curr. Opin. Struct. Biol. 6, 663-670

18 Roden, L. (1980) The Biochemistry of Glycoproteins and Proteoglycans, Lennarz, W.G., ed, 269-314, Plenum, NY

19 Almeida, R., Levery, S.B., Mandel, U., Kresse, H., Schwientek, T, Bennett, E.P., and Clausen, H. (1999) Cloning and expression of a proteoglycan UDP-galactose:betaxylose beta1,4-galactosyltransferase I. A seventh member of the human beta4galactosyltransferase gene family. J. Biol. Chem. 274, 26165-26171

20 Okajima, T., Fukumoto, S., Furukawa, K., Urano, T., and Furukawa, K. (1999) Molecular basis for the progeroid variant of Ehlers-Danlos syndrome. Identification and characterization of two mutations in galactosyltransferase I gene. J. Biol. Chem. 274, 28841-28844

21 Furukawa, K., and Okajima, T. (2002) Galactosyltransferase I is a gene responsible for progeroid variant of Ehlers-Danlos syndrome: molecular cloning and identification of mutations. Biochim. Biophys. Acta 1573, 377-381

22 Ramakrishnan, B., and Qasba, P.K. (2010) Crystal structure of the catalytic domain of drosophila \{beta\}1,4-galactosyltransferase-7. J. Biol. Chem. 285, 15619-15626

23 Daligault, F., Rahuel-Clermont, S., Gulberti, S, Branlant, G, Netter, P., Magdalou, J., and Lattard, V. (2009) Thermodynamic insights into the structural basis governing the donor substrate recognition by human beta1,4-galactosyltransferase 7. Biochem. J. 418, 605-614

24 Esko, J.D., Weinke, J.L., Taylor, W.H., Ekborg, G., Roden, L., Anatharamaiah, G., and Gawish, A. (1987) Inhibition of chondroitin and heparan sulfate biosynthesis in Chinese hamster ovary cell mutants defective in galactosyltransferase I. J. Biol. Chem. 262, 12189-12195

25 Bradford, M.M. (1976) A rapid and sensitive method for the quantitation of microgram quantities of protein utilizing the principle of protein-dye binding. Anal. Biochem. 72, 248-254 
26 Ha, Y.W., Jeon, B.T., Moon, S.H., Toyoda, H., Toida, T., Lindhardt, R.J. and Kim, Y.S. (2005) Characterization of heparan sulfate from the unossified antler of Cervus elaphus. Carbohydr. Res. 340, 411-416

27 Turnbull, W.B. and Danaras, A.H. (2003) On the value of c: can low affinity systems be studied by isothermal titration calorimetry. J. Am. Chem. Soc. 125, 14859-14866

28 Nakamura, Y., Haines, N., Chen, J., Okajima, T., Furukawa, K., Urano, T., Stanley, P., Irvine, K.D., and Furukawa, K. (2002) Identification of a Drosophila gene encoding xylosylprotein beta4-galactosyltransferase. J. Biol. Chem. 277, 46280-46288

29 Takemae, H., Ueda, R., Okubo, R., Nakato, H., Izumi, S., Saigo, K., and Nishihara, S. (2003) Proteoglycan UDP-galactose:beta-xylose beta 1,4-galactosyltransferase I is essential for viability in Drosophila melanogaster. J. Biol. Chem. 278, 15571-15578.

30 Dam, T.K., and Brewer, C.F. (2002) Thermodynamic studies of lectin-carbohydrate interactions by isothermal titration calorimetry. Chem. Rev. 102, 387-429

31 Chervenak, M.C., and Toone, E.J. (1995) Calorimetric analysis of the binding of lectins with overlapping carbohydrate-binding ligand specificities. Biochemistry 34, 5685-5695

32 Xie, H., Bolam, D.N., Nagy, T., Szabo, L., Cooper, A., Simpson, P.J., Lakey, J.H., Williamson, M.P., and Gilbert, H.J. (2001) Role of hydrogen bonding in the interaction between a xylan binding module and xylan. Biochemistry 40, 5700-5707

33 Ramakrishnan, B., Boeggeman, E., Ramasamy, V., and Qasba, P.K. (2004) Structure and catalytic cycle of beta-1,4-galactosyltransferase. Curr. Opin. Struct. Biol. 14, 593600 .

34 Hennet, T. (2002) The galactosyltransferase family. Cell. Mol. Life Sci. 59, 1081-1095

35 Amado, M., Almeida, R., Schwientek, T., and Clausen, H. (1999) Identification and characterization of large galactosyltransferase gene families: galactosyltransferases for all functions. Biochim. Biophys. Acta 1473, 35-53

36 Herman, T., and Horvitz, H.R. (1999) Three proteins involved in Caenorhabditis elegans vulval invagination are similar to components of a glycosylation pathway. Proc. Natl. Acad. Sci. USA 96, 974-979

37 Almeida, R., Amado, M., David, L., Levery, S.B., Holmes, E.H., Merkx, G., Van Kessel, A.G., Ryggaard, E., Hassan, H., Bennett, E., and Clause, H.(1997) A family of human beta4-galactosyltransferases. Cloning and expression of two novel UDPgalactose:beta-n-acetylglucosamine beta1, 4-galactosyltransferases, beta4Gal-T2 and beta4Gal-T3. J. Biol. Chem. 272, 31979-31992

38 Okayama, M., Kimata, K., and Suzuki, S. (1973) The influence of p-nitrophenyl beta-dxyloside on the synthesis of proteochondroitin sulfate by slices of embryonic chick cartilage. J.Biochem. Tokyo 74, 1069-1073

39 Schwartz, N.B. Galligani, L., Ho, P.L., and Dorfman, A. (1974) Stimulation of synthesis of free chondroitin sulfate chains by beta-D-xylosides in cultured cells. Proc. Natl. Acad. Sci. USA 71, 4047-4051

40 Lugemwa, F.N., Sarkar, A.K., and Esko, J.D. (1996) Unusual beta-D-xylosides that prime glycosaminoglycans in animal cells. J. Biol. Chem. 271, 19159-19165 


\section{TABLES}

Table 1 Apparent kinetic parameters of the membrane wild type and mutated $\beta 1,4$ GalTs7 expressed in $\mathrm{CHO618}$ cells towards donor (i.e., UDP-Gal) and acceptor substrates (i.e., pNP-Xyl)

To determine the $\beta 1$,4-galactosyltransferase activity, standard reactions were performed in $100 \mathrm{mM}$ cacodylate buffer ( $\mathrm{pH}$ 7.0) containing $10 \mathrm{mM} \mathrm{MnCl}_{2}$ and 0.3 to $0.6 \mathrm{~g} . \mathrm{l}^{-1}$ of total proteins containing membrane wild type or mutant $\beta 1,4-G a l T 7$. The $k_{\mathrm{obs}}$ values determined at saturating concentration of both substrates were evaluated after normalization of the $\beta 1,4-$ GalT7 expression level by immunoquantification by western blotting as described in Experimental procedures. Each data point represents the mean $\pm 2 \mathrm{SD}$ of three individual determinations. nd, not determined. " $\mathrm{p}<0.05$ compared to $\beta 1,4-$ GalT7. nd, not determined; - , activity not detected.

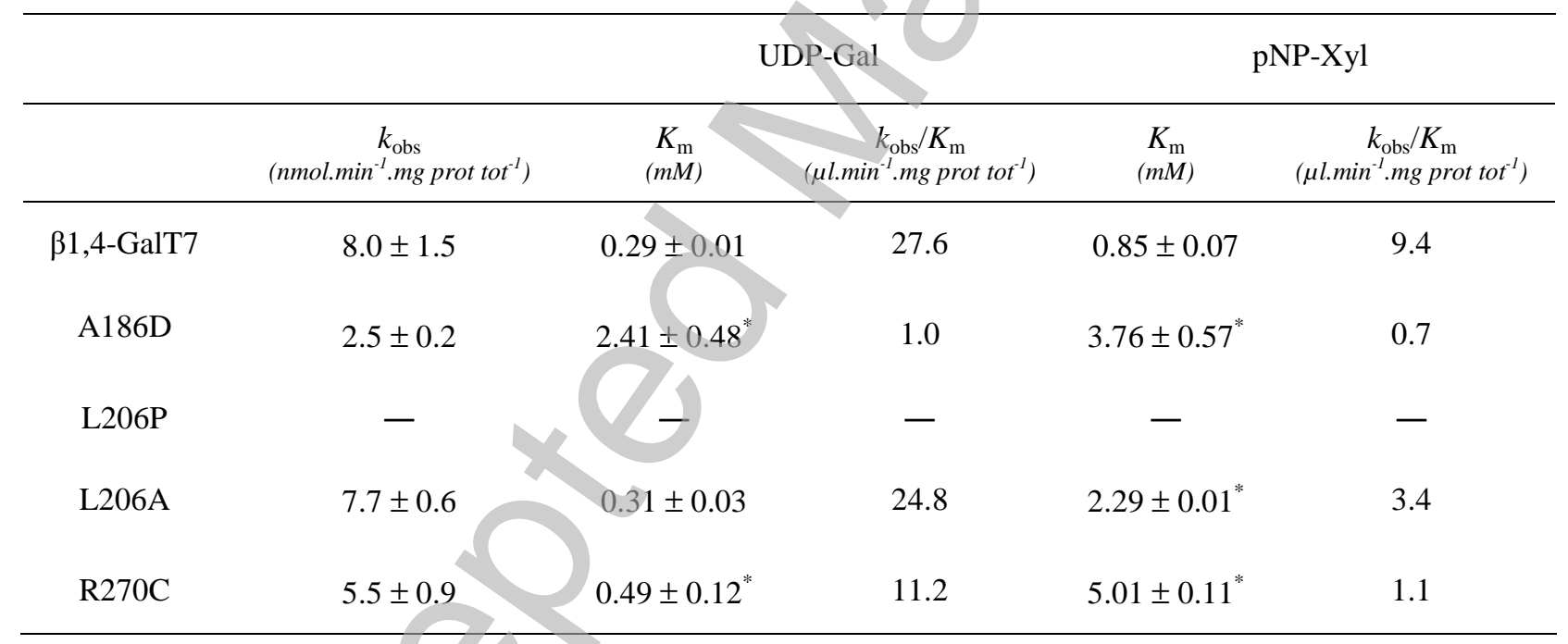


Table 2 Kinetic parameters of purified MBP-A186D ${ }_{\text {aa82, MBP-L206P }}$ a82 and MBP$\mathrm{R270C}_{\mathrm{aa82}}$ towards donor substrate (i.e., UDP-Gal) and acceptor substrates (i.e., $4 \mathrm{MU}$ Xyl and pNP-Xyl)

Standard reactions were performed in $100 \mathrm{mM}$ cacodylate buffer (pH 7.0) containing $10 \mathrm{mM} \mathrm{MnCl}_{2}$ and 0.04 to $0.2 \mu \mathrm{M}$ of purified truncated MBP-proteins. Each data point represents the mean \pm 2 SD of three or more individual determinations. ${ }^{*} \mathrm{p}<0.05$ compared to the results obtained with $\mathrm{MBP}_{\mathrm{W}} \mathrm{WT} \mathrm{T}_{\mathrm{aa} 2}$. Because the purities of the MBP-A186 $\mathrm{D}_{\text {aa82 }}$ and MBP-L206P $\mathrm{P}_{\text {aa82 }}$ can be estimated to be 90 and $65 \%$, the $\mathrm{k}_{\text {cat }}$ values are underestimated and rather correspond to $\sim 66$ and $100 \mathrm{~min}^{-1}$, respectively.

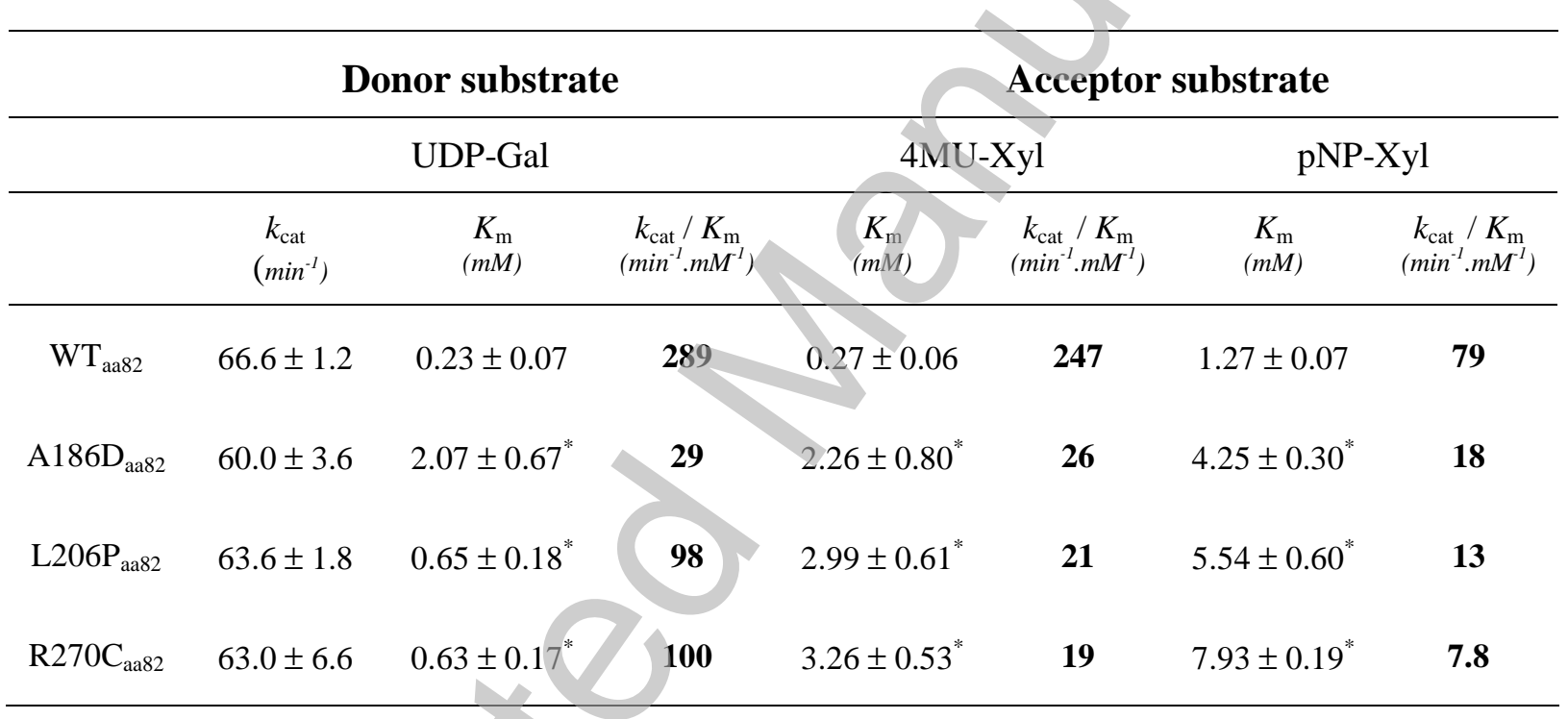


Table 3 Kinetic parameters of the purified MBP-WT aa82, $_{\text {MBP-WT }}$ aal, MBP-L206P aa82 $_{\text {al }}$ and MBP-L206 $\mathrm{P}_{\mathrm{aa}}$ expressed in Escherichia coli towards UDP-Gal and towards 4MUXyl

Standard reactions were performed in $100 \mathrm{mM}$ cacodylate buffer ( $\mathrm{pH} 7.0$ ) containing $10 \mathrm{mM} \mathrm{MnCl}_{2}, 0.04$ to 1 $\mu \mathrm{M}$ of purified fused proteins. Kinetic parameters for 4MU-Xyl and UDP-Gal were obtained after the addition of increasing amounts of acceptor or donor substrates $(0.02$ to $10 \mathrm{mM}$ of $4 \mathrm{MU}-\mathrm{Xyl}$ in the presence of $10 \mathrm{mM}$ of UDP-Gal ; 0.025 to $10 \mathrm{mM}$ of donor substrates in the presence of $10 \mathrm{mM}$ of $4 \mathrm{MU}-\mathrm{Xyl})$ to the standard reaction.

Each data point represents the mean \pm 2 SD of three individual determinations. nd, not determined.

\begin{tabular}{|c|c|c|c|c|c|}
\hline & \multicolumn{3}{|c|}{ UDP-Gal } & \multicolumn{2}{|c|}{ 4MU-Xyl } \\
\hline & $\begin{array}{c}k_{\mathrm{cat}} \\
\left(\mathrm{min}^{-1}\right)\end{array}$ & $\begin{array}{l}K_{\mathrm{m}} \\
(m M)\end{array}$ & $\underset{\left(\min ^{-1} \cdot m M^{-1}\right)}{k_{\mathrm{cat}} / K_{\mathrm{m}}}$ & $\begin{array}{c}K_{\mathrm{m}} \\
(m M)\end{array}$ & $\underset{\left(\min ^{-1} \cdot m M^{-1}\right)}{k_{\mathrm{ca}} / K_{\mathrm{m}}}$ \\
\hline $\mathrm{WT}_{\mathrm{aa} 82}$ & $66.6 \pm 1.2$ & $0.23 \pm 0.07$ & 289 & $27 \pm 0.06$ & 247 \\
\hline $\mathrm{WT}_{\text {aa1 }}$ & $1.7 \pm 0.06$ & $0.80 \pm 0.10$ & & $0.62 \pm 0.02$ & 2.74 \\
\hline $\mathrm{L} 206 \mathrm{P}_{\mathrm{aa} 82}$ & $63.6 \pm 1.8$ & $0.65 \pm 0.18$ & & $2.99 \pm 0.61$ & 21 \\
\hline $\mathrm{L}_{206 \mathrm{P}_{\mathrm{aa} 1}}$ & $<0.05$ & nd & & nd & nd \\
\hline
\end{tabular}


Table 4 Thermodynamic parameters for the binding of UDP to the MBP-WT aa82, $_{\text {MBP- }}$ A186D $_{\text {aa82 }}$ and MBP-R270C $\mathrm{Cas2}_{\mathrm{a} 2}$

ITC experiments were carried out at $30^{\circ} \mathrm{C}$ in MOPS $(20 \mathrm{mM})$ buffer $(\mathrm{pH} 7.0)$ containing $\mathrm{NaCl}(150 \mathrm{mM})$ with $\mathrm{MnCl}_{2}(5 \mathrm{mM})$ using a VP-ITC MicroCalorimeter (Micro Cal, Inc.) Each data point represents the mean $\pm 2 \mathrm{SD}$ of three individual determinations. * $\mathrm{p}<0.01$ compared to WT.

\begin{tabular}{cccccc}
\hline & $\begin{array}{c}\Delta G \\
(\mathrm{cal} / \mathrm{mol})\end{array}$ & $\begin{array}{c}\Delta H \\
(\mathrm{kcal} / \mathrm{mol})\end{array}$ & $\begin{array}{c}\Delta S \\
(\mathrm{cal} / \mathrm{mol} / \mathrm{K})\end{array}$ & $\begin{array}{c}-T \Delta S \\
(\mathrm{kcal} / \mathrm{mol})\end{array}$ & $\begin{array}{c}K_{\mathrm{d}} \\
(\mu \mathrm{M})\end{array}$ \\
\hline $\mathrm{WT}_{\text {aa82 }}$ & $-6880 \pm 160$ & $-22.9 \pm 4.8$ & -54 & 16.07 & 9.0 \\
${\mathrm{~A} 186 \mathrm{D}_{\text {aa82 }}}$ & $-6030 \pm 40$ & $-8.1 \pm 1.3^{*}$ & $-6.9^{*}$ & $2.08^{*}$ & $38^{*}$ \\
$\mathrm{R}^{*} 70 \mathrm{C}_{\text {aа82 }}$ & $-6580 \pm 70$ & $-21.0 \pm 2.3$ & -48.5 & 14.44 & 15 \\
\hline
\end{tabular}

Table 5 Thermodynamic parameters for the binding of pNP-Xyl to the MBP-WT aa82, MBP-A186D ${ }_{\mathrm{aa82}}$ and MBP-R270C $\mathrm{Ca}_{\mathrm{a} 2}$

ITC experiments were carried out at $30^{\circ} \mathrm{C}$ in MOPS $(20 \mathrm{mM})$ buffer $(\mathrm{pH} 7.0)$ containing $\mathrm{NaCl}(150 \mathrm{mM})$ with $\mathrm{MnCl}_{2}(5 \mathrm{mM})$ and UDP $(5 \mathrm{mM})$ using a VP-ITC Microcalorimeter (Micro Cal, Inc.) Each data point represents the mean \pm 2 SD of three individual determinations. nd, not determined.

\begin{tabular}{cccccc}
\hline & $\begin{array}{c}\Delta G \\
(\mathrm{cal} / \mathrm{mol})\end{array}$ & $\begin{array}{c}\Delta H \\
(\mathrm{kcal} / \mathrm{mol})\end{array}$ & $\begin{array}{c}\Delta S \\
(\mathrm{cal} / \mathrm{mol} / \mathrm{K})\end{array}$ & $\begin{array}{c}-T \Delta S \\
(\mathrm{kcal} / \mathrm{mol})\end{array}$ & $\begin{array}{c}K_{\mathrm{d}} \\
(\mathrm{mM})\end{array}$ \\
\hline $\mathrm{WT}_{\mathrm{aa} 22}$ & $-3180 \pm 10$ & $-11.8 \pm 0.2$ & -29 & 8.60 & 4.6 \\
${\mathrm{~A} 186 \mathrm{D}_{\text {aa82 }}}$ & $-3040 \pm 80$ & $-24.8 \pm 5.4$ & -73 & 21.83 & 5.8 \\
${\mathrm{R} 270 \mathrm{C}_{\mathrm{aa82}}}$ & nd & nd & nd & nd & $>10$ \\
\hline
\end{tabular}




\section{FIGURE LEGENDS}

Figure 1 Immunoblot analysis of membrane fraction of $\mathrm{CHO618}$ cells expressing wild type and mutant $\beta 1,4-G a l T 7$.

Membrane protein (10 $\mu \mathrm{g}$ ) containing wild type- (lane 1), A186D- (lane 2), L206P- (lane 3), R270C- (lane 4) and L206A- $\beta 1,4-$-GalTs7 (lane 5) were loaded. The $\beta 1,4-G a l T 7$ proteins were probed with primary antibody directed against the c-myc tag.

Figure 2 Analysis of purified recombinant human wild type and mutant $\beta 1,4-G a l T 7$ fused-proteins by SDS-PAGE.

Human wild type and mutant $\beta 1,4-G a l T 7$ were expressed in E. coli as fused-proteins with the maltose-binding protein, and then, purified onto an amylose column, as described in Experimental procedures. Purified proteins $(2 \mu \mathrm{g})$ MBP-R270C aa82 $_{\text {(lane 1), MBP-L206P }}$ a82 (lane 2), MBP-A186D aa82 (lane 3), MBP-WT aa82 (lane 4), MBP${\mathrm{L} 206 \mathrm{P}_{\text {aal }} \text { (lane 6) and MBP-WT }}_{\text {aal }}$ (lane 7) and protein marker (i.e., 25, 37, 75, 100 and $150 \mathrm{kDa}$ (lane 5) were analysed by electrophoresis on polyacrylamide gel $(10 \%, w / v)$ in the presence of SDS and then, stained with Coomassie blue.

Figure 3 Calorimetric profiles of the donor and acceptor substrate analogues binding to MBP-A186D ${ }_{\text {aa82, }}$ compared to MBP-WT aa82 $_{\text {. }}$

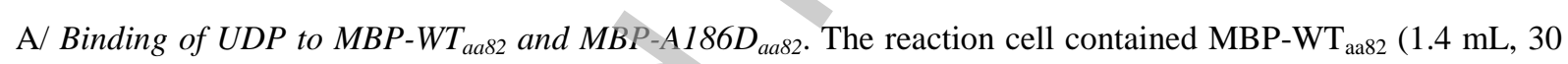
$\mu \mathrm{M}$, black line) or MBP-A186 $\mathrm{D}_{\text {aa82 }}(1.4 \mathrm{~mL}, 50 \mu \mathrm{M}$, gray line $)$ in $20 \mathrm{mM}$ MOPS buffer containing $150 \mathrm{mM}$ $\mathrm{NaCl}$ and $5 \mathrm{mM}$ of $\mathrm{MnCl}_{2}$. The syringe contained $0.5 \mathrm{mM}$ and $1 \mathrm{mM}$ UDP in the same buffer, for MBP-WT ${ }_{\text {aa82 }}$ and MBP-A186Daa82, respectively. Top, raw calorimetric data obtained from the injection of UDP at 4-min intervals. The bottom plot shows the integrated binding isotherm with the experimental points and the corresponding best fit, providing values for thermodynamic parameters. B/ Binding of $p N P$-Xyl to $M B P$-WT $a$ a 82 and MBP-A186D $D_{a a 82}$. The reaction cell contained MBP-WT $\mathrm{Ta}_{\text {aa } 2}\left(1.4 \mathrm{~mL}, 30 \mu \mathrm{M}\right.$, black line) or MBP-A186 $\mathrm{D}_{\text {aa82 }}$ (1.4 mL, $25 \mu \mathrm{M}$, gray line) in $20 \mathrm{mM}$ MOPS buffer containing $150 \mathrm{mM} \mathrm{NaCl}$ containing $5 \mathrm{mM}$ of $\mathrm{MnCl}_{2}$ and 5 mM UDP. The syringe contained $40 \mathrm{mM}$ pNP-Xyl in the same buffer. Top, raw calorimetric data obtained from the injection of pNP-Xyl at 4-min intervals. The bottom plot shows the integrated binding isotherm with the experimental points and the corresponding best fit, providing values for thermodynamic parameters.

Figure 4 Restoration of GAG synthesis in $\mathrm{CHO618}$ cells after wild type or mutant $\beta 1,4-$ GalT7 transfection.

CHO618 cells were transfected with pcDNA- $\beta 1,4-G a l T 7$ or -A186D or -L206P or -R270C, then labeled, two days after transfection, with $\mathrm{Na}_{2}\left[{ }^{35} \mathrm{~S}_{\mathrm{SO}_{4}}(10 \mu \mathrm{Ci} / \mathrm{mL})\right.$ for $9 \mathrm{~h}$. The labelled ${ }^{35} \mathrm{~S}$-GAGs were isolated by papain digestion and successive acetate potassium, and CPC-precipitations. Respective $\beta 1,4-G a l T 7$ expression was analyzed by western blot using anti-myc antibodies, as described in the Experimental Procedures. 
Figure 5 Stimulation kinetics of GAG synthesis by 4MU-Xyl in $\mathrm{CHO618}$ cells expressing wild type or mutated $\beta 1,4-G a I T s 7$.

CHO618 cells were transfected with pcDNA- $\beta 1,4-G a 1 T 7$ or -A186D or -L206P or -R270C, then, two days after transfection, incubated with various concentrations of $4 \mathrm{MU}-\mathrm{Xyl}(0$ to $1 \mu \mathrm{M})$ and labeled, in the same time, with $\mathrm{Na}_{2}\left[{ }^{35} \mathrm{~S}_{\mathrm{SO}_{4}}(10 \mu \mathrm{Ci} / \mathrm{mL})\right.$ for $9 \mathrm{~h}$. The labelled ${ }^{35} \mathrm{~S}-\mathrm{GAGs}$ were isolated by papain digestion and successive acetate potassium-, and $\mathrm{CPC}$-precipitations. 


\section{Figure 1}




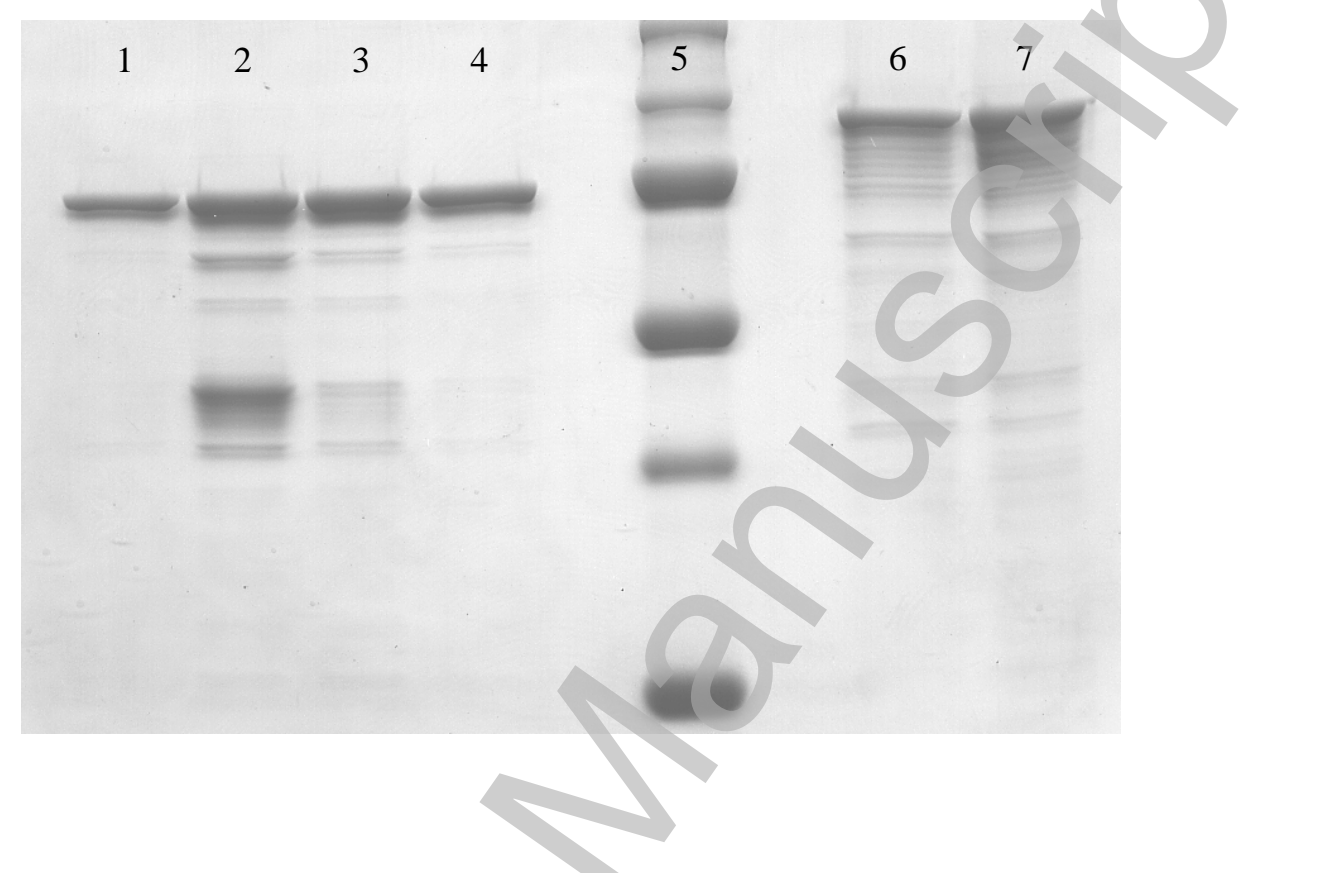

Figure 2 
A /

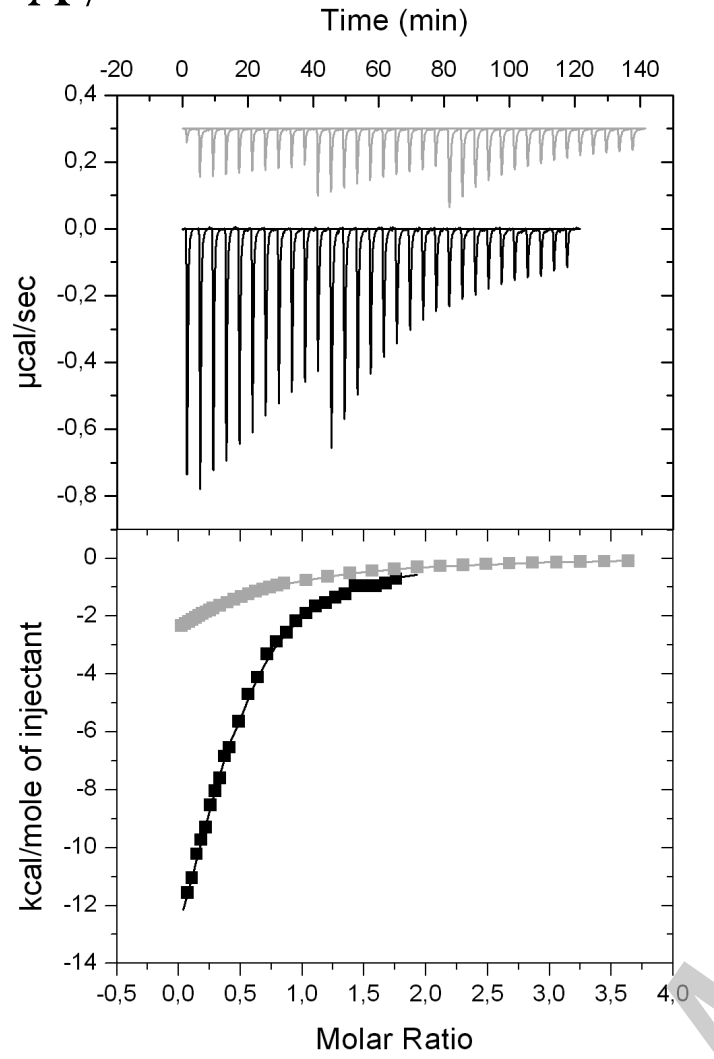

B /

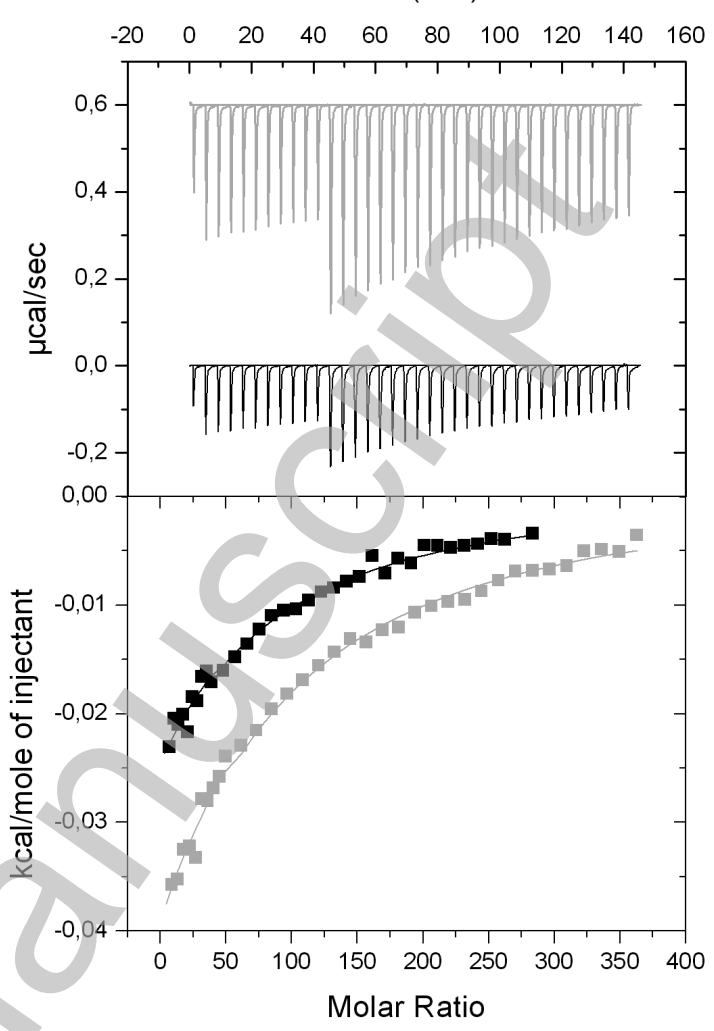

Figure 3 


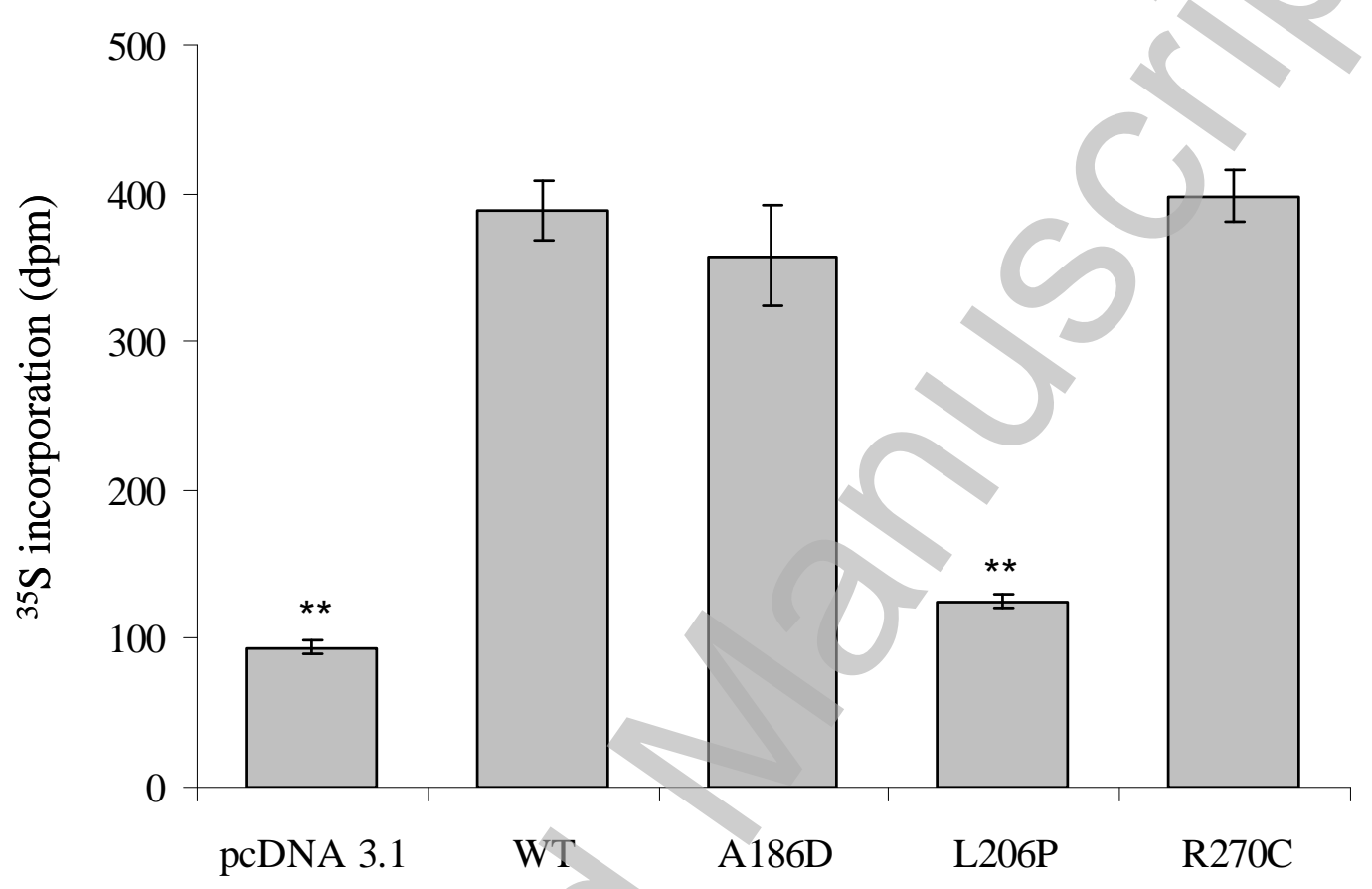

Figure 4 


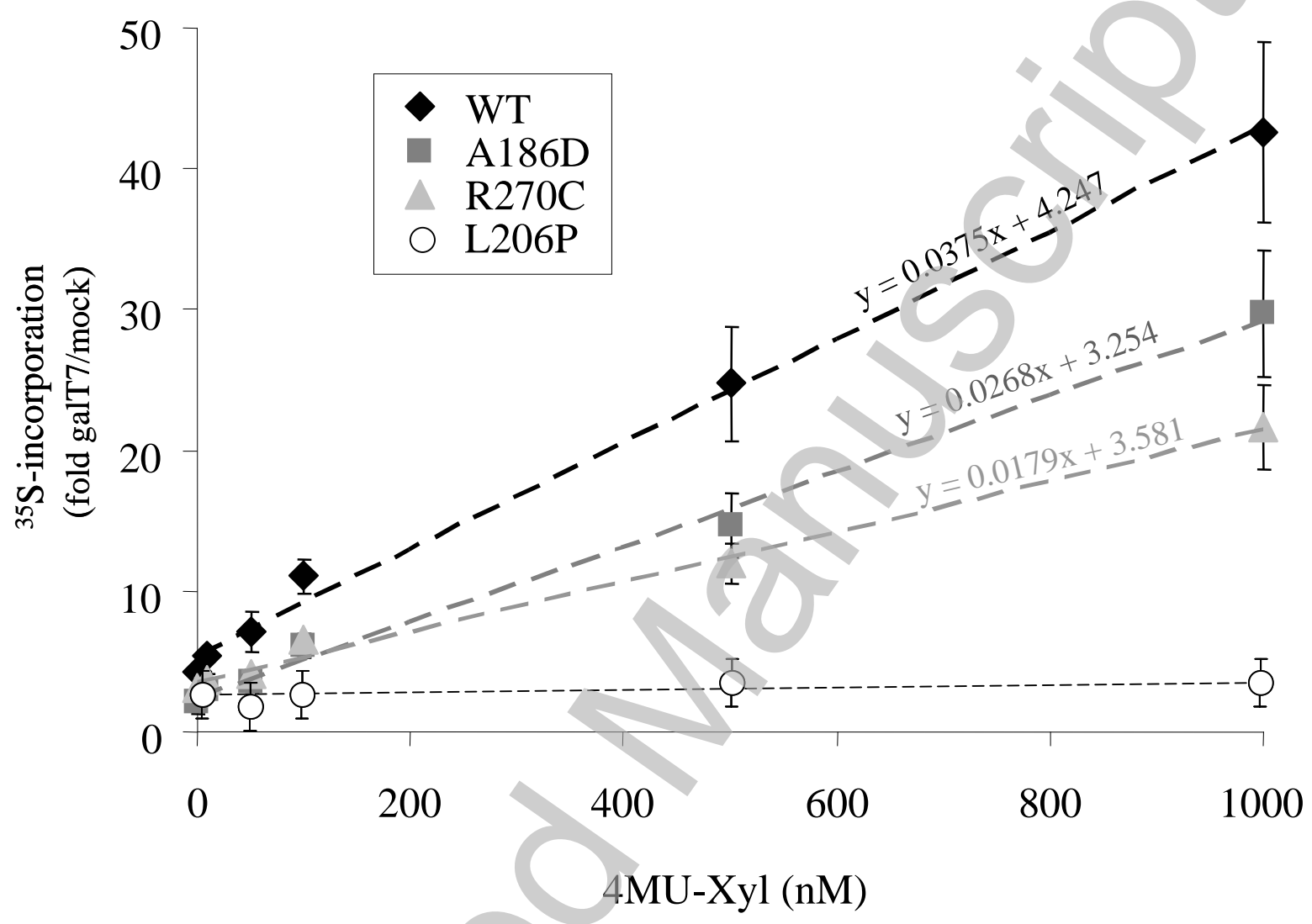

Figure 5 